\title{
Brief Test of Attention: Normative data for the Latin American Spanish speaking adult population
}

D. Rivera ${ }^{\mathrm{a}}$, P.B. Perrin ${ }^{\mathrm{b}}$, A. Aliaga ${ }^{\mathrm{c}}$, M.T. Garza ${ }^{\mathrm{d}}$, C.P. Saracho ${ }^{\mathrm{e}}$, W. Rodríguez ${ }^{\mathrm{f}}$, E. Justo-Guillen ${ }^{\mathrm{g}}$, A. Aguayo ${ }^{\mathrm{h}}, \mathrm{S}$. Schebela ${ }^{\mathrm{i}}, \mathrm{S}$. Gulin ${ }^{\mathrm{b}}$, C. Weil ${ }^{\mathrm{j}}$, M. Longoni $^{\mathrm{k}}$, N. Ocampo-Barba ${ }^{\mathrm{l}}$, J. Galarza-del-Angel ${ }^{\mathrm{m}}$, D. Rodríguez ${ }^{\mathrm{n}}$, L. Esenarro $^{\mathrm{o}}$, P. García-Egan ${ }^{\mathrm{p}}$, C. Martínez ${ }^{\mathrm{q}}$ and J.C. Arango-Lasprilla ${ }^{\mathrm{a}, \mathrm{r}, *}$

${ }^{\mathrm{a}}$ Faculty of Psychology and Education, University of Deusto, Bilbao, Spain

${ }^{\mathrm{b}}$ Department of Psychology, Virginia Commonwealth University, Richmond, USA

${ }^{\mathrm{c}}$ Servicio Médico Legal, Ministerio de Justicia, Santiago, Chile

${ }^{\mathrm{d}}$ Facultad de Psicología, Universidad Autónoma de Nuevo León, Monterrey, Mexico

${ }^{\mathrm{e}}$ CETYS University, Mexicali, Mexico

${ }^{\mathrm{f}}$ Ponce Health Sciences University, Ponce, Puerto Rico

${ }^{\mathrm{g}}$ Instituto Nacional de Neurología y Neurocirugía MVS, Mexico City, Mexico

${ }^{\mathrm{h}}$ Instituto Vocacional Enrique Díaz de León, Guadalajara, Mexico

i Instituto de Prevención Social, Asunción, Paraguay

${ }^{\mathrm{j}}$ Escuela de Psicología, Universidad Dr. José Matías Delgado, San Salvador, El Salvador

${ }^{\mathrm{k}}$ Clínica de rehabilitación Las Araucarias, Buenos Aires, Argentina

${ }^{1}$ Fundación Horizontes, Santa Cruz de la Sierra, Bolivia

${ }^{\mathrm{m}}$ Universidad Autónoma de Baja California, Mexicali, Mexico

${ }^{\mathrm{n}}$ Centro investigaciones Medico Quirúrgicas CIMEQ, Havana, Cuba

${ }^{\circ}$ Instituto de Neuropsicología y Demencias, Lima, Peru

${ }^{\mathrm{p}}$ Departamento de Psicología, Universidad del Valle de Guatemala, Guatemala City, Guatemala

${ }^{\mathrm{q}}$ Departamento de Medicina de Rehabilitación, Nacional Autónoma de Honduras, Tegucigalpa, Honduras

${ }^{\mathrm{r}}$ IKERBASQUE, Basque Foundation for Science, Bilbao, Spain

\begin{abstract}
.
OBJECTIVE: To generate normative data on the Brief Test of Attention (BTA) across 11 countries in Latin America, with country-specific adjustments for gender, age, and education, where appropriate.

METHOD: The sample consisted of 3,977 healthy adults who were recruited from Mexico, Argentina, Peru, Paraguay, Honduras, Chile, Cuba, Puerto Rico, Guatemala, El Salvador, and Bolivia. Each subject was administered the BTA as part of a larger neuropsychological battery. A standardized five-step statistical procedure was used to generate the norms.

RESULTS: The final multiple linear regression models explained between 11-41\% of the variance in BTA scores. Although men had higher scores on the BTA in Honduras, there were no other significant gender differences, and this one effect size was small. As a result, gender-adjusted norms were not generated.

CONCLUSIONS: This is the first normative multicenter study conducted in Latin America to create norms for the BTA; this study will have an impact on the future practice of neuropsychology throughout Latin America.
\end{abstract}

Keywords: Normative data, Brief Test of Attention, Reference values, Latin America, auditory-divided attention

*Address for correspondence: Juan Carlos Arango-Lasprilla, Ph.D., IKERBASQUE Research Professor, Department of Psychology, University of Deusto, IKERBASQUE, Basque Foundation for Science, Bilbao, Spain. Tel.: +34 804859 4329; E-mail: jcarango@deusto.es. 


\section{Introduction}

The Brief Test of Attention (BTA; Schretlen, 1997) is a commonly used neuropsychological measure of auditory-divided attention that was developed to reduce the influence of confounding task demands such as motor speed and visual scanning (Schretlen, Bobholz, \& Brandt, 1996a). Although many tests of attention require visual acuity or manual dexterity, a primary advantage of the BTA is that it can be used with individuals with visual and/or motor impairments (Schretlen, 1997).

The BTA is based on a theoretical framework proposed by Cooley and Morris (1990), which conceptualizes the components of the attention system and discusses the task demands of attention tests. Because administration time is only 10 minutes, the instrument is often administered bedside to detect attentional impairments (Strauss, Sherman, \& Spreen, 2006). The test was originally validated on individuals aged 17 to 82 years (Schretlen et al., 1996a). Additional normative data have been presented for a child sample aged 6 to 14 (Schretlen at al., 1996a).

The BTA consists of two parallel forms, each orally presented using an audio CD (Schretlen, 1997). Each form contains a list of alpha-numeric strings which increase in length from four to 18 characters. In the first list (Form N), the examinee is asked to count how many numbers have been presented, while disregarding the letters. The exact same items are presented on the second list (Form L), but this time the individual's task is to count the number of letters presented while ignoring the letters (Schretlen, 1997). Correct responses receive a score of 1 , with each list ranging in score from 0 to 10. The number of correctly identified items is summed across both forms, with total raw scores falling between 0 and 20 (Schretlen, 1997).

In contrast to digit span tasks, the subject is not asked to recall which numbers or letters were presented by the audiotape. Also, the test author emphasizes that the BTA was designed to identify deficits in attention rather than to differentiate between levels of normal attention (Schretlen, 1997).

Besides Schretlen et al.'s (1996) original norms study, the BTA has been validated for use in patients with Huntington's disease and amnesia. This study demonstrated that non-demented Huntington's disease patients performed more poorly on the BTA compared to normal controls (Schretlen, Brandt, \& Bobholz, 1996b). However, the authors did not find any group differences between non-demented amnesic patients and normal adults, suggesting that intact memory is not necessary for successful performance (Schretlen et al., 1996b). In addition, Valos (2006) established validity of the BTA amongst children who had sustained moderate and severe traumatic brain injury.

The BTA is a widely used measure of attention in the neuropsychological literature. It has been used in studies of traumatic brain injury (Rao et al., 2010; Wong, 1999), Parkinson's disease (Tröster et al., 1997), sleep apnea (Aloia et al., 2003), and cancer (Butler et al., 2008; Correa et al., 2004), as well as psychological disorders such as bipolar disorder and schizophrenia (Schretlen et al., 2007).

In regard to ecological validity, the BTA has demonstrated high sensitivity (Strauss et al., 2006). Compared to other tests of cognitive ability (e.g., VIQ, PIQ, FAS), for example, the BTA was more sensitive in predicting functional competence, such as activities of daily living, among adults with severe mental disorders (Schretlen, Jayaram, Maki, Robinson, \& Devilliers, 1997). In addition, the BTA been shown to be significantly correlated with psychosocial outcome among TBI patients (Schretlen, 1992)

The BTI's reliability is good based on the normative data, with a high coefficient alpha for the whole test $(r=0.80)$. When the two forms (Forms $\mathrm{L}$ and $\mathrm{N}$ ) are compared separately, coefficients are $r=0.69$ and 0.65 , respectively. In a group of older normal adults with mild hypertension tested at a 9-month interval, test-retest stability was 0.70 (Schretlen, 1997).

An examination of correlations with other neuropsychological instruments shows that the BTA correlates more strongly with measures of attention than with other cognitive tests (e.g., the Rey-Osterrieth, Boston Naming Test; Schretlen et al., 1996a). For example, the BTA correlates with Digits Backward and Forward (0.53 and 0.43, respectively) as well as Trails A and B (-0.55 and 0.48, respectively; Schretlen, 1997). A study of head injury patients found that the BTA is particularly significantly correlated with backward digit span and trail making B (Wong, 1999). Also, the BTA was shown to be more sensitive to impairments in mild head injury patients than both Trails A and B (Wong, 1999). Among normal adults, the BTA strongly correlates with all parts of the Stroop $(r=0.66-0.68)$, and among patients, the BTA has the highest correlations with the Stroop interference trial (Schretlen, 1997).

Several demographic effects (e.g., age, gender, and ethnicity) have been reported; however, they tend to be fairly minimal (Schretlen, 1997). Performance on the BTA is consistently negatively associated with 
age, such that starting at about age 60, performance begins to decline (Schretlen, 1997). Schretlen (1997) also reported gender effects, with women performing marginally better than men. There are also subtle race/ethnicity effects, such that African American adults score slightly lower than Caucasian adults. In the highest age group, however, African American adults slightly outperform Caucasians (Schretlen, 1997). Because demographic variables are only nominally associated with performance on the BTA, standardized scores are based solely on age (Schretlen, 1997; Strauss et al., 2006).

Despite the measure's widespread use, only three validation studies have been completed (Schretlen et al., 1996a, 1996b; Valos, 2006). The normative development sample consisted of individuals between the ages of 17 and 82 who were geographically located in the United States (either Baltimore, Maryland or Buffalo, New York; Schretlen et al., 1996a). Men comprised $37 \%$ of the sample and women comprised $63 \%$. The majority were Caucasian (82\%), with $18 \%$ identifying as African-American and $0.3 \%$ identifying as other (Schretlen et al., 1996a).

Although numerous neuropsychological studies use the BTA as a measure of attention, the normative group was both geographically and ethnically restrictive, and norms have not yet been established for Hispanic individuals or people living in Latin America. Given the instrument's substantial advantages (e.g., its brevity and ease of use for individuals with motor and/or visual impairments), the purpose of the present study was to create normative data for healthy adult population across 11 countries in Latin America.

\section{Method}

\subsection{Participants}

The sample consisted of 3,977 healthy individuals who were recruited from Argentina, Bolivia, Chile, Cuba, El Salvador, Guatemala, Honduras, Mexico, Paraguay, Peru, and, Puerto Rico. The participants were selected according to the following criteria: a) were between 18 to 95 years of age, b) were born and currently lived in the country where the protocol was conducted, c) spoke Spanish as their native language, d) had completed at least one year of formal education, e) were able to read and write at the time of evaluation, f) scored $\geq 23$ on the Mini-Mental State Examination (MMSE, Folstein, Folstein, \& McHugh, 1975), g) scored $\leq 4$ on the Patient Health Questionnaire-9
(PHQ-9, Kroenke, Spitzer, \& Williams, 2001), and h) scored $\geq 90$ on the Barthel Index (Mahoney \& Barthel, 1965).

Participants with self-reported neurologic or psychiatric disorders were excluded due to a potential effect on cognitive performance. Participants were volunteers from the community and signed an informed consent. Seven participants were excluded from the analyses, with a final sample of 3,970 participants. Socio-demographic and participant characteristics for each of the countries' samples have been reported elsewhere (Guàrdia-Olmos, Peró-Cebollero, Rivera, \& Arango-Lasprilla, 2015). The multi-center study was approved by the Ethics Committee of the coordinating site, the University of Deusto, Spain.

\subsection{Instrument administration}

The BTA test consists of two equivalent forms that are administered consecutively (Forms $\mathrm{N}$ and $\mathrm{L}$ ). In the $\mathrm{N}$ form, the subject hears a list of 10 series of letters and numbers that are intercalated (for example: " $5-\mathrm{K}-7$ $-\mathrm{H}$ "), after which the subject must indicate how many numbers were mentioned. The series of letters and numbers increase in length, from 4 to 18 items (Schretlen, et al., 1996a; Spreen \& Strauss, 1998). Subsequently, in the form $\mathrm{L}$, the subjects are presented the same list series, but this time the subject must indicate how many letters were mentioned (Schretlen et al., 1996a). The test is done while the subject holds his or her hands and keeps them in view of the examiner, in this way the subject is unable to count with fingers (Spreen \& Strauss, 1998). The total score of each form is equal to the number of correct answers, and the total score is the sum of the scores in the forms $\mathrm{N}$ and $\mathrm{L}$ (Schretlen et al., 1996a).

\subsection{Statistical analyses}

The detailed statistical analyses used to generate the normative data for this test are described in GuàrdiaOlmos, et al. 2015. In summary, the data manipulation process for each country-specific dataset involved five steps: a) $t$ - tests for independent samples and effect sizes $(r)$ were conducted to determine gender effects. If the effect size was larger than 0.3 , gender was included in the model with gender dummy coded and female as the reference group $($ male $=1$ and female $=0)$. b) A multivariable regression model was used to specify the predictive model including gender (if effect size was 
Table 1

Effect of gender in the BTA

\begin{tabular}{|c|c|c|c|c|c|c|}
\hline Country & Gender & Mean (SD) & $t$ & df & Sig. (2-tailed) & $r$ \\
\hline \multirow[t]{2}{*}{ Argentina } & Male & $16.3(2.8)$ & 1.38 & 318 & 0.169 & 0.077 \\
\hline & Female & $15.8(2.9)$ & & & & \\
\hline \multirow[t]{2}{*}{ Bolivia } & Male & 12.4 (3.9) & 1.29 & 272 & 0.199 & 0.078 \\
\hline & Female & $11.8(4.2)$ & & & & \\
\hline \multirow[t]{2}{*}{ Chile } & Male & $13.7(3.9)$ & 1.29 & 318 & 0.199 & 0.072 \\
\hline & Female & $13.1(4.2)$ & & & & \\
\hline \multirow[t]{2}{*}{ Cuba } & Male & $14.0(3.8)$ & -0.30 & 304 & 0.761 & 0.017 \\
\hline & Female & $14.1(3.8)$ & & & & \\
\hline \multirow[t]{2}{*}{ El Salvador } & Male & $12.0(4.8)$ & 0.65 & 254 & 0.515 & 0.041 \\
\hline & Female & $11.6(4.1)$ & & & & \\
\hline \multirow[t]{2}{*}{ Guatemala } & Male & $14.8(3.4)$ & -0.41 & 212 & 0.680 & 0.028 \\
\hline & Female & $15.0(3.8)$ & & & & \\
\hline \multirow[t]{2}{*}{ Honduras } & Male & $12.0(4.8)$ & 3.72 & 179 & $<0.001^{* * *}$ & 0.268 \\
\hline & Female & $9.1(5.1)$ & & & & \\
\hline \multirow[t]{2}{*}{ Mexico } & Male & $14.5(3.8)$ & 1.23 & 1,297 & 0.221 & 0.034 \\
\hline & Female & $14.2(3.9)$ & & & & \\
\hline \multirow[t]{2}{*}{ Paraguay $^{\mathrm{a}}$} & Male & $7.8(4.0)$ & 1.63 & 172.2 & 0.106 & 0.123 \\
\hline & Female & $7.1(3.0)$ & & & & \\
\hline \multirow[t]{2}{*}{ Peru } & Male & $15.2(3.1)$ & -0.27 & 242 & 0.784 & 0.018 \\
\hline & Female & $15.3(3.4)$ & & & & \\
\hline \multirow[t]{2}{*}{ Puerto Rico } & Male & $16.1(2.9)$ & 0.03 & 291 & 0.977 & 0.002 \\
\hline & Female & $16.1(3.3)$ & & & & \\
\hline
\end{tabular}

${ }^{a}$ Value of the $t$-test for independent groups from the different variances with the corresponding correction of Yuen-Welch of degrees of freedom. $* * * p<0.001$.

larger than 0.3), age as a continuous variable, and education as a dummy coded variable with 1 if the participant had $>12$ years of education and 0 if the participant had 1-12 years of education. If gender, age and/or education was not statistically significant in this multivariate model with an alpha of 0.05 , the non-significant variables were removed, and the model was re-run. Then a final regression model was conducted that included age (if statistically significant in the multivariable model), dichotomized education (if statistically significant in the multivariate model), and/or gender (if effect size was greater than 0.3) $\left[\hat{y}_{i}=\beta_{o}+\left(\beta_{\text {Age }}\right.\right.$. Age $\left._{i}\right)+\left(\beta_{\text {Educ }} \cdot\right.$ Educ $\left._{i}\right)+\left(\beta_{\text {Gender }} \cdot\right.$ Gender $\left.\left.\left._{i}\right)\right] ; \mathrm{c}\right)$ residual scores were calculated based on this final model $\left.\left(e_{i}=y_{i}-\hat{y}_{i}\right) ; \mathrm{d}\right)$ using the $S D$ (residual) value provided by the regression model, residuals were standardized: $z=e_{i} / S D_{e}$, with $S D_{e}($ residual $)=$ the standard deviation of the residuals in the normative sample; and e) standardized residuals were converted to percentile values (Strauss et al., 2006). Using each country's dataset, these steps were applied to BTA scores.

\section{Results}

Regarding the effect of gender on BTA scores, the $t$-tests showed significant differences between men and women in Honduras; however, it did not have an effect size larger than 0.3. Table 1 shows the results of the gender analyses by country on BTA scores. As shown in Table 1, the effect sizes for all countries were less than 0.3 , and therefore gender was not taken into account to generate BTA normative data for any of the countries in the study.

The final eleven BTA multivariate linear regression models for each country are shown in Table 2 . In all countries, the BTA score increased for those with more than 12 years of education (see Table 2) and, in all countries except Guatemala, BTA scores decreased in a linear fashion as a function of age. The amount of variance explained in BTA scores ranged from $11 \%$ (in Mexico) to $41 \%$ (in Paraguay).

\subsection{Normative procedure}

Norms (e.g., a percentile score) for the BTA scores were established using the five-step procedure described above. To facilitate the understanding of the procedure to obtain the percentile associated with a score on this test, an example will be given. Suppose you need to find the percentile score for a Bolivian woman, who is 60 years old and has 7 years of education. She has a score of 12 on the BTA. The steps to obtain the percentile for this score are: a) Check Table 1 to determine if the effect size of gender 
Table 2

Final multiple linear regression models for BTA

\begin{tabular}{|c|c|c|c|c|c|c|c|}
\hline Country & & $\mathrm{B}$ & Std. Error & $t$ & Sig. & $\mathrm{R}^{2}$ & $S D_{e}$ (residual) \\
\hline \multirow[t]{3}{*}{ Argentina } & (Constant) & 16.797 & 0.434 & 38.740 & $<0.001$ & 0.139 & 2.658 \\
\hline & Age & -0.036 & 0.008 & -4.641 & $<0.001$ & & \\
\hline & Education & 1.437 & 0.302 & 4.763 & $<0.001$ & & \\
\hline \multirow[t]{3}{*}{ Bolivia } & (Constant) & 14.942 & 0.654 & 22.836 & $<0.001$ & 0.147 & 3.786 \\
\hline & Age & -0.059 & 0.011 & -5.556 & $<0.001$ & & \\
\hline & Education & 1.943 & 0.610 & 3.187 & 0.002 & & \\
\hline \multirow[t]{3}{*}{ Chile } & (Constant) & 16.288 & 0.685 & 23.763 & $<0.001$ & 0.189 & 3.679 \\
\hline & Age & -0.063 & 0.011 & -5.760 & $<0.001$ & & \\
\hline & Education & 2.221 & 0.500 & 4.439 & $<0.001$ & & \\
\hline \multirow[t]{3}{*}{ Cuba } & (Constant) & 16.581 & 0.566 & 29.309 & $<0.001$ & 0.219 & 3.331 \\
\hline & Age & -0.061 & 0.010 & -6.239 & $<0.001$ & & \\
\hline & Education & 2.865 & 0.451 & 6.348 & $<0.001$ & & \\
\hline \multirow[t]{3}{*}{ El Salvador } & (Constant) & 13.842 & 0.684 & 20.250 & $<0.001$ & 0.301 & 3.671 \\
\hline & Age & -0.056 & 0.011 & -5.034 & $<0.001$ & & \\
\hline & Education & 4.961 & 0.566 & 8.765 & $<0.001$ & & \\
\hline \multirow[t]{2}{*}{ Guatemala } & (Constant) & 13.910 & 0.294 & 47.299 & $<0.001$ & 0.129 & 3.384 \\
\hline & Education & 2.683 & 0.478 & 5.613 & $<0.001$ & & \\
\hline \multirow[t]{3}{*}{ Honduras } & (Constant) & 14.050 & 1.047 & 13.420 & $<0.001$ & 0.187 & 4.680 \\
\hline & Age & -0.094 & 0.019 & -4.862 & $<0.001$ & & \\
\hline & Education & 2.590 & 0.832 & 3.113 & 0.002 & & \\
\hline \multirow[t]{3}{*}{ Mexico } & (Constant) & 16.788 & 0.296 & 56.725 & $<0.001$ & 0.106 & 3.654 \\
\hline & Age & -0.052 & 0.005 & -10.396 & $<0.001$ & & \\
\hline & Education & 1.200 & 0.246 & 4.881 & $<0.001$ & & \\
\hline \multirow[t]{3}{*}{ Paraguay } & (Constant) & 8.844 & 0.699 & 12.649 & $<0.001$ & 0.405 & 2.650 \\
\hline & Age & -0.044 & 0.012 & -3.663 & $<0.001$ & & \\
\hline & Education & 4.793 & 0.467 & 10.254 & $<0.001$ & & \\
\hline \multirow[t]{3}{*}{ Peru } & (Constant) & 15.190 & 0.539 & 28.182 & $<0.001$ & 0.259 & 2.856 \\
\hline & Age & -0.040 & 0.009 & -4.376 & $<0.001$ & & \\
\hline & Education & 2.765 & 0.391 & 7.081 & $<0.001$ & & \\
\hline \multirow[t]{3}{*}{ Puerto Rico } & (Constant) & 18.300 & 0.578 & 31.639 & $<0.001$ & 0.144 & 2.921 \\
\hline & Age & -0.052 & 0.010 & -5.412 & $<0.001$ & & \\
\hline & Education & 1.031 & 0.355 & 2.899 & $<0.004$ & & \\
\hline
\end{tabular}

in the country of interest (Bolivia) on this test and time point (BTA) is greater than 0.3 by country. The column labeled $r$ in Table 1 indicates the effect size. In this example, the effect size is 0.078 , which is not greater than 0.3. For Bolivian on this test, gender does not influence scores to a sufficient degree to take it into account gender when determining the percentile. b) Find Bolivia in Table 2, which provides the final regression models by country for BTA. Use the B weights to create an equation that will allow you to obtain the predicted BTA score. The corresponding B weights are multiplied by the actual age and dichotomized education scores and added to a constant in order to calculate the predicted value. In this case, the predicted BTA score would be calculated using the equation $\left[\hat{y}_{i}=14.942+\left(-0.059 \cdot\right.\right.$ Age $\left._{i}\right)+$ (1.943 - Dichotomized Educational Level $i)$ (the values have been rounded for presentation in the formula). The subscript notation $i$ indicates the person of interest. The person's age is 60 , but the education variable is not continuous in the model. Years of education is split into either 1 to 12 years (and assigned a 0 ) or more than 12 years (and assigned a 1) in the model. Since our hypothetical person in the example has 7 years of education, her educational level value is 0 . Thus the predicted value is $\hat{y}_{i}=14.942+(-0.059 \cdot 60)+(1.943 \cdot 0)=$ $14.942-3.517+0=11.424$. c) In order to calculate the residual value (indicated with an e in the equation), we subtract the actual value from the predicted value we just calculated $\left(e_{i}=y_{i}-\hat{y}_{i}\right)$. In this case, it would be $e_{i}=12-11.42=0.576$. d) Next, consult the $S D_{e}$ column in Table 2 to obtain the country-specific $S D_{e}$ (residual) value. For Bolivia, it is 3.786. Using this value, we can transform the residual value to a standardized $z$ score using the equation $\left(e_{i} / S D_{e}\right)$. In this case, we have 0.576/3.786 $=0.152$. This is the standardized $z$ score for a Bolivian woman aged 60 and 7 years of education and a score of 12 on the BNT. e) The last step is to use look up the tables in the statistical reference books (e.g. Strauss et al., 2006) or use a trusted online calculator like the one 
available at http://www.measuringu.com/pcalcz.php. In the online calculator, you would enter the $z$ score and choose a one-sided test and note the percent of area after hitting the submit button. In this case, the probability of 0.152 corresponds to the 56th percentile.

\subsection{User-friendly normative data Tables}

The five-step normative procedures explained above can provide more individualized norms. However, this method can be prone to human error due to the number of required computations. To enhance user-friendliness, the authors have completed these steps for a range of raw scores based on small age range groupings (see Guàrdia-Olmos, et al., 2015) and created tables so that clinicians can more easily use to obtain a percentile range associated with a given raw score on this test. These tables are available by country and type of test (BTA) in the Appendix. In order to obtain an approximate percentile for the above example (converting a raw score of 12 for a Bolivian women who is 60 years old and has 7 years of education) using the simplified normative tables provided, the following steps are recommended. (1) First, identify the appropriate table ensuring the specific country and test. In this case, the table for BTA scores for Bolivia can be found in Table A2. (2) Note if the title of the table indicates that it is only to be used for one specific gender. In this case, gender is not specified. Thus Table A2 is used for both males and females. (3) Next, the table is divided based on educational level ( 1 to 12 vs. more than 12 years of education). Since this woman has 7 years of education, she falls into the " 1 to 12 years of education" category. These data can be found in the low section of the table. (4) Determine the age range most appropriate for the individual. In this case, 60 fall into the column 58-62 years of age. (5) Read down the age range column to find the approximate location of the raw score the person obtained on the test. Reading down the 58-62 column, the score of 12 obtained by this Bolivian woman corresponds to an approximate percentile of 60 .

The percentile obtained via this user-friendly table method (60th) is slightly different than the more exact one (56th) obtained following the individual conversion steps above because the table method is based on an age range (e.g., individuals aged 58-62) instead of the exact age (individuals aged 60). If the exact score is not listed in the column, you must estimate the percentile value from the listed raw scores.

\section{Discussion}

The purpose of the current study was to generate normative data on the BTA across 11 countries in Latin America, with country-specific adjustments for gender, age, and education, where appropriate. The final multiple linear regression models explained between $11-41 \%$ of the variance in BTA scores. Although men had higher scores on the BTA in Honduras, there were no other significant gender differences, and this one effect size in Honduras was small. As a result, genderadjusted norms were not generated. These findings are generally in line with the previous literature which has found that gender effects are quite minimal on the BTA, although one previous study found women to perform marginally better than men (Schretlen, 1997). In light of the previous literature, the current results suggest that gender should not be taken into account in calculating participants' percentiles for the BTA in Latin America when using the current norms.

BTA scores increased linearly as a function of education in all countries. To the authors' knowledge, no previous studies have found BTA scores to be associated with education, so this likely represents a unique finding from the current study. As a result, neuropsychologists should use education-adjusted norms generated for each country when administering the BTA in that country, especially because of potentially major differences in the quality of education in different regions of Latin America.

BTA scores were inversely associated with age in all countries in the current study, and as a result, ageadjusted norms are presented by country. These age findings are similar to those from previous studies which have shown lower BTA scores in older adults, especially starting at age 60 when performance begins to decline (Schretlen, 1997). Similarly to education, neuropsychologists in Latin America should use the age-adjusted norms by country generated in the current study.

\subsection{Limitations and future directions}

This study has several limitations, and as a result directions for future research. First, this study was subject to a number of sampling limitations. First, although the BTA is an extremely common neuropsychological measure in Latin America, many other common assessments need to be normed in the same manner as the current study. Future research should examine the psychometrics of other common instruments in Latin 
America. Research should also examine the ecological validity of various neuropsychological assessments in this region, and if not, create instruments in those cultures that have better ecological validity. Indeed, the BTA has been shown to have good sensitivity in predicting activities of daily living among adults with severe mental disorders (Schretlen et al., 1997), but nonetheless the BTA was created in a Western culture that may differ from those in Latin America. Future research should develop culturally sensitive assessments within local cultures, not just translate and norm tests from other cultures and countries as occurred in the current study.

Second, participants all spoke Spanish as their primary language, but BTA performance could be different among people who speak various secondary languages. An important area for future research is bilingualism and performance on the BTA which was not assessed in the current study. Also, the data were collected in specific regions of the countries in the current study, not nationally. This study represents the largest neuropsychological normative study in the history of Latin America for the BTA, as well as in any global region, but it is only a first step in for larger studies with nationally representative samples. Many participants had fewer than 12 years of education, but those unable to read or write were excluded. As a result, the norms from the current study are limited in their ability to generalize to illiterate adults. Similarly, participants in the current study were excluded if they had a history of neurological conditions, so future studies should include neurological populations, as well as children.

Third, clinicians exercise caution in applying the BTA norms from this study to individuals in countries beyond the 11 countries from which data were collected. Future studies should establish BTA norms in other Latin American countries including as Ecuador, Uruguay, Venezuela, and Panama. However, these BTA norms may be more accurate in those countries than other norms currently in use. This generalizability is a critical area for future research.

Despite these limitations and because no Spanish norms have yet been established for the BTA, this study was the first to generate BTA norms across 11 countries in Latin America with nearly 4,000 participants. As a result, this was the largest and most comprehensive BTA normative study conducted in any global region, and its norms will likely affect the standard of neuropsychological assessment with the BTA in Latin America unlike any study before it.

\section{References}

Aloia, M.S., Ilniczky, N., Di Dio, P., Perlis, M.L., Greenblatt, D.W., \& Giles, D.E (2003). Neuropsychological changes and treatment compliance in older adults with sleep apnea. Journal of Psychosomatic Research, 54(1), 71-76. doi: 10.1016/S00223999(02)00548-2

Butler, R. W., Copeland, D. R., Fairclough, D. L., Mulhern, R. K., Katz, E. R., Kazak, A. E., \& Sahler, O. J. Z. (2008). A multicenter, randomized clinical trial of a cognitive remediation program for childhood survivors of a pediatric malignancy. Journal of Consulting and Clinical Psychology, 76(3), 367-378. doi: 10.1037/0022-006X.76.3.367

Cooley, E. L., \& Morris, R. D. (1990). Attention in children: A neuropsychologically based model for assessment. Developmental Neuropsychology, 6(3), 239-274. doi: 10.1080/87565649009540465

Correa, D. D., DeAngelis, L. M., Shi, W., Thaler, H., Glass, A., \& Abrey, L. E. (2004). Cognitive functions in survivors of primary central nervous system lymphoma. Neurology, 62(4), 548-555. doi: 10.1093/neuonc/nor186

Folstein M.F., Folstein S.E., \& McHugh P.R. (1975). "Mini-mental state": A practical method for grading the cognitive state of patients for the clinician. Journal of psychiatric research, 12(3), 189-198.

Guàrdia-Olmos, J., Peró-Cebollero, M., Rivera, D., \& ArangoLasprilla, J.C. (2015). Methodology for the development of normative data for ten Spanish-language neuropsychological tests in eleven Latin American countries. NeuroRehabilitation, 37, 493-499.

Kroenke, K., Spitzer, R.L., \& Williams, J.B. (2001). The PHQ-9. Journal of General Internal Medicine, 16(9), 606-613.

Mahoney, F.I., \& Barthel, D. (1965). Functional evaluation: The Barthel Index. Maryland State Medical Journal, 14, 56-61.

Rao, V., Bertrand, M., Rosenberg, P., Makley, M., Schretlen, D. J., Brandt, J., \& Mielke, M. M. (2010). Predictors of new-onset depression after mild traumatic brain injury. The Journal of Neuropsychiatry and Clinical Neurosciences, 22(1), 100-104. doi: 10.1176/appi.neuropsych.22.1.100

Schretlen, D. (1992). Accounting for variance in long-term recovery from traumatic brain injury with executive abilities and injury severity [Abstract]. Journal of Clinical and Experimental Neuropsychology, 14, 77.

Schretlen D. (1997). Brief test of attention professional manual Psychological Assessment Resources, Odessa. FL.

Schretlen, D. J., Cascella, N. G., Myer, S. M., Kingery, L. R., Testa, S. M., Munro, C. A., et al. (2007). Neuropsychological functioning in bipolar disorder and schizophrenia. Biological Psychiatry, 62(2), 179-186. doi: 10.1016/j.biopsych.2006.09.025

Schretlen, D., Bobholz, J., \& Brandt, J. (1996a). Development and psychometric properties of the brief test of attention. Clinical Neuropsychologist, 10(1), 80-89. doi: 10.1080/13854049608406666

Schretlen, D., Brandt, J., \& Bobholz, J. H. (1996b). Validation of the brief test of attention in patients with Huntington's disease and amnesia. Clinical Neuropsychologist, 10(1), 90-95. doi: 10.1080/13854049608406667

Schretlen D., Jayaram G., Maki P., Robinson H., \& Devilliers C. (1997). Functional correlates of neurocognitive deficits in adults with severe mental disorders [Abstract]. Journal of the International Neuropsychological Society, 3, 25. 
Spreen, O., \& Strauss, E. (1998). A compendium of neuropsychological tests: Administration, norms, and commentary (2nd ed.) Oxford University Press, New York.

Strauss, E., Sherman, E.M., \& Spreen, O. (2006). A Compendium of Neuropsychological Tests: Administration, Norms, and Commentary. New York: Oxford University Press.

Tröster, A. I., Fields, J. A., Wilkinson, S. B., Pahwa, R., Miyawaki, E., Lyons, K. E., \& Koller, W. C. (1997). Unilateral pallidal stimulation for Parkinson's disease: Neurobehavioral functioning before and 3 months after electrode implantation. Neurology, 49(4), 1078-1083. doi: 10.1212/WNL.49.4.1078
Valos A.M. (2006). Validity and sensitivity of the Brief Test of Attention for children who have sustained moderate and severe traumatic brain injury. Dissertation Abstracts International: Section B: The Sciences and Engineering, 66(7-B), 3962.

Wong, T. M. (1999). Validity and sensitivity of the brief test of attention with acute brain injury and mild head injury patients. [Abstract]. Archives of Clinical Neuropsychology, 14(8), 617-818. 
Table A1

Normative data for the BTA stratified by age and education levels for ARGENTINA

\begin{tabular}{|c|c|c|c|c|c|c|c|c|c|c|c|c|c|c|}
\hline & \multirow[b]{2}{*}{ Percentile } & \multicolumn{13}{|c|}{ Age (Years) } \\
\hline & & $18-22$ & $23-27$ & $28-32$ & $33-37$ & $38-42$ & $43-47$ & $48-52$ & $53-57$ & $58-62$ & $63-67$ & $68-72$ & $73-77$ & $>77$ \\
\hline \multirow{13}{*}{ 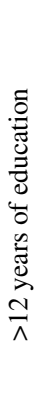 } & 95 & - & - & - & - & - & - & 20.0 & 20.0 & 20.0 & 20.0 & 20.0 & 19.9 & 19.7 \\
\hline & 90 & - & - & 20.0 & 20.0 & 20.0 & 20.0 & 19.8 & 19.7 & 19.5 & 19.3 & 19.1 & 19.0 & 18.8 \\
\hline & 85 & 20.0 & 20.0 & 19.9 & 19.7 & 19.6 & 19.4 & 19.2 & 19.0 & 18.8 & 18.7 & 18.5 & 18.3 & 18.1 \\
\hline & 80 & 19.8 & 19.6 & 19.4 & 19.2 & 19.0 & 18.9 & 18.7 & 18.5 & 18.3 & 18.1 & 18.0 & 17.8 & 17.6 \\
\hline & 70 & 18.9 & 18.7 & 18.5 & 18.4 & 18.2 & 18.0 & 17.8 & 17.6 & 17.5 & 17.3 & 17.1 & 16.9 & 16.8 \\
\hline & 60 & 18.2 & 18.0 & 17.8 & 17.6 & 17.5 & 17.3 & 17.1 & 16.9 & 16.7 & 16.6 & 16.4 & 16.2 & 16.0 \\
\hline & 50 & 17.5 & 17.3 & 17.2 & 17.0 & 16.8 & 16.6 & 16.4 & 16.3 & 16.1 & 15.9 & 15.7 & 15.5 & 15.4 \\
\hline & 40 & 16.9 & 16.7 & 16.5 & 16.3 & 16.1 & 16.0 & 15.8 & 15.6 & 15.4 & 15.2 & 15.1 & 14.9 & 14.7 \\
\hline & 30 & 16.1 & 16.0 & 15.8 & 15.6 & 15.4 & 15.2 & 15.1 & 14.9 & 14.7 & 14.5 & 14.3 & 14.2 & 14.0 \\
\hline & 20 & 15.3 & 15.1 & 14.9 & 14.7 & 14.6 & 14.4 & 14.2 & 14.0 & 13.9 & 13.7 & 13.5 & 13.3 & 13.1 \\
\hline & 15 & 14.8 & 14.6 & 14.4 & 14.2 & 14.0 & 13.9 & 13.7 & 13.5 & 13.3 & 13.1 & 13.0 & 12.8 & 12.6 \\
\hline & 10 & 14.1 & 13.9 & 13.8 & 13.6 & 13.4 & 13.2 & 13.0 & 12.9 & 12.7 & 12.5 & 12.3 & 12.1 & 12.0 \\
\hline & 5 & 13.2 & 13.0 & 12.8 & 12.6 & 12.4 & 12.3 & 12.1 & 11.9 & 11.7 & 11.5 & 11.4 & 11.2 & 11.0 \\
\hline \multirow{13}{*}{ 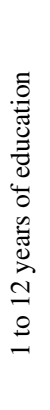 } & 95 & 20.0 & 20.0 & 20.0 & 19.9 & 19.7 & 19.5 & 19.4 & 19.2 & 19.0 & 18.8 & 18.6 & 18.5 & 18.3 \\
\hline & 90 & 19.5 & 19.3 & 19.1 & 18.9 & 18.8 & 18.6 & 18.4 & 18.2 & 18.1 & 17.9 & 17.7 & 17.5 & 17.3 \\
\hline & 85 & 18.8 & 18.7 & 18.5 & 18.3 & 18.1 & 17.9 & 17.8 & 17.6 & 17.4 & 17.2 & 17.1 & 16.9 & 16.7 \\
\hline & 80 & 18.3 & 18.1 & 18.0 & 17.8 & 17.6 & 17.4 & 17.2 & 17.1 & 16.9 & 16.7 & 16.5 & 16.3 & 16.2 \\
\hline & 70 & 17.5 & 17.3 & 17.1 & 16.9 & 16.7 & 16.6 & 16.4 & 16.2 & 16.0 & 15.9 & 15.7 & 15.5 & 15.3 \\
\hline & 60 & 16.7 & 16.6 & 16.4 & 16.2 & 16.0 & 15.8 & 15.7 & 15.5 & 15.3 & 15.1 & 15.0 & 14.8 & 14.6 \\
\hline & 50 & 16.1 & 15.9 & 15.7 & 15.5 & 15.4 & 15.2 & 15.0 & 14.8 & 14.6 & 14.5 & 14.3 & 14.1 & 13.9 \\
\hline & 40 & 15.4 & 15.2 & 15.1 & 14.9 & 14.7 & 14.5 & 14.3 & 14.2 & 14.0 & 13.8 & 13.6 & 13.4 & 13.3 \\
\hline & 30 & 14.7 & 14.5 & 14.3 & 14.2 & 14.0 & 13.8 & 13.6 & 13.4 & 13.3 & 13.1 & 12.9 & 12.7 & 12.5 \\
\hline & 20 & 13.8 & 13.7 & 13.5 & 13.3 & 13.1 & 13.0 & 12.8 & 12.6 & 12.4 & 12.2 & 12.1 & 11.9 & 11.7 \\
\hline & 15 & 13.3 & 13.1 & 13.0 & 12.8 & 12.6 & 12.4 & 12.2 & 12.1 & 11.9 & 11.7 & 11.5 & 11.3 & 11.2 \\
\hline & 10 & 12.7 & 12.5 & 12.3 & 12.1 & 12.0 & 11.8 & 11.6 & 11.4 & 11.2 & 11.1 & 10.9 & 10.7 & 10.5 \\
\hline & 5 & 11.7 & 11.5 & 11.4 & 11.2 & 11.0 & 10.8 & 10.6 & 10.5 & 10.3 & 10.1 & 9.9 & 9.8 & 9.6 \\
\hline
\end{tabular}

Table A2

Normative data for the BTA stratified by age and education levels for BOLIVIA

\begin{tabular}{|c|c|c|c|c|c|c|c|c|c|c|c|c|c|c|}
\hline & \multirow[b]{2}{*}{ Percentile } & \multicolumn{13}{|c|}{ Age (Years) } \\
\hline & & $18-22$ & $23-27$ & $28-32$ & $33-37$ & $38-42$ & $43-47$ & $48-52$ & $53-57$ & $58-62$ & $63-67$ & $68-72$ & $73-77$ & $>77$ \\
\hline \multirow{13}{*}{ 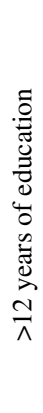 } & 95 & - & - & - & 20.0 & 20.0 & 20.0 & 20.0 & 19.9 & 19.6 & 19.3 & 19.0 & 18.7 & 18.4 \\
\hline & 90 & 20.0 & 20.0 & 20.0 & 19.7 & 19.4 & 19.1 & 18.8 & 18.5 & 18.2 & 17.9 & 17.6 & 17.3 & 17.0 \\
\hline & 85 & 19.6 & 19.4 & 19.1 & 18.8 & 18.5 & 18.2 & 17.9 & 17.6 & 17.3 & 17.0 & 16.7 & 16.4 & 16.1 \\
\hline & 80 & 18.9 & 18.6 & 18.3 & 18.0 & 17.7 & 17.4 & 17.1 & 16.8 & 16.5 & 16.3 & 16.0 & 15.7 & 15.4 \\
\hline & 70 & 17.7 & 17.4 & 17.1 & 16.8 & 16.5 & 16.2 & 15.9 & 15.6 & 15.3 & 15.0 & 14.7 & 14.5 & 14.2 \\
\hline & 60 & 16.7 & 16.4 & 16.1 & 15.8 & 15.5 & 15.2 & 14.9 & 14.6 & 14.3 & 14.0 & 13.7 & 13.4 & 13.1 \\
\hline & 50 & 15.7 & 15.4 & 15.1 & 14.8 & 14.5 & 14.2 & 14.0 & 13.7 & 13.4 & 13.1 & 12.8 & 12.5 & 12.2 \\
\hline & 40 & 14.8 & 14.5 & 14.2 & 13.9 & 13.6 & 13.3 & 13.0 & 12.7 & 12.4 & 12.1 & 11.8 & 11.5 & 11.2 \\
\hline & 30 & 13.7 & 13.5 & 13.2 & 12.9 & 12.6 & 12.3 & 12.0 & 11.7 & 11.4 & 11.1 & 10.8 & 10.5 & 10.2 \\
\hline & 20 & 12.5 & 12.2 & 11.9 & 11.7 & 11.4 & 11.1 & 10.8 & 10.5 & 10.2 & 9.9 & 9.6 & 9.3 & 9.0 \\
\hline & 15 & 11.8 & 11.5 & 11.2 & 10.9 & 10.6 & 10.3 & 10.0 & 9.7 & 9.4 & 9.1 & 8.8 & 8.6 & 8.3 \\
\hline & 10 & 10.9 & 10.6 & 10.3 & 10.0 & 9.7 & 9.4 & 9.1 & 8.8 & 8.5 & 8.2 & 7.9 & 7.6 & 7.3 \\
\hline & 5 & 9.5 & 9.2 & 8.9 & 8.6 & 8.3 & 8.0 & 7.7 & 7.5 & 7.2 & 6.9 & 6.6 & 6.3 & 6.0 \\
\hline \multirow{13}{*}{ 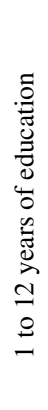 } & 95 & 20.0 & 19.7 & 19.4 & 19.1 & 18.8 & 18.5 & 18.2 & 17.9 & 17.6 & 17.3 & 17.0 & 16.8 & 16.5 \\
\hline & 90 & 18.6 & 18.3 & 18.0 & 17.7 & 17.4 & 17.1 & 16.9 & 16.6 & 16.3 & 16.0 & 15.7 & 15.4 & 15.1 \\
\hline & 85 & 17.7 & 17.4 & 17.1 & 16.8 & 16.5 & 16.2 & 15.9 & 15.7 & 15.4 & 15.1 & 14.8 & 14.5 & 14.2 \\
\hline & 80 & 16.9 & 16.7 & 16.4 & 16.1 & 15.8 & 15.5 & 15.2 & 14.9 & 14.6 & 14.3 & 14.0 & 13.7 & 13.4 \\
\hline & 70 & 15.7 & 15.4 & 15.2 & 14.9 & 14.6 & 14.3 & 14.0 & 13.7 & 13.4 & 13.1 & 12.8 & 12.5 & 12.2 \\
\hline & 60 & 14.7 & 14.4 & 14.1 & 13.8 & 13.5 & 13.2 & 13.0 & 12.7 & 12.4 & 12.1 & 11.8 & 11.5 & 11.2 \\
\hline & 50 & 13.8 & 13.5 & 13.2 & 12.9 & 12.6 & 12.3 & 12.0 & 11.7 & 11.4 & 11.1 & 10.8 & 10.5 & 10.3 \\
\hline & 40 & 12.8 & 12.5 & 12.2 & 11.9 & 11.7 & 11.4 & 11.1 & 10.8 & 10.5 & 10.2 & 9.9 & 9.6 & 9.3 \\
\hline & 30 & 11.8 & 11.5 & 11.2 & 10.9 & 10.6 & 10.3 & 10.0 & 9.7 & 9.5 & 9.2 & 8.9 & 8.6 & 8.3 \\
\hline & 20 & 10.6 & 10.3 & 10.0 & 9.7 & 9.4 & 9.1 & 8.8 & 8.5 & 8.2 & 8.0 & 7.7 & 7.4 & 7.1 \\
\hline & 15 & 9.8 & 9.5 & 9.2 & 9.0 & 8.7 & 8.4 & 8.1 & 7.8 & 7.5 & 7.2 & 6.9 & 6.6 & 6.3 \\
\hline & 10 & 8.9 & 8.6 & 8.3 & 8.0 & 7.8 & 7.5 & 7.2 & 6.9 & 6.6 & 6.3 & 6.0 & 5.7 & 5.4 \\
\hline & 5 & 7.6 & 7.3 & 7.0 & 6.7 & 6.4 & 6.1 & 5.8 & 5.5 & 5.2 & 4.9 & 4.6 & 4.3 & 4.0 \\
\hline
\end{tabular}


Table A3

Normative data for the BTA stratified by age and education levels for CHILE

\begin{tabular}{|c|c|c|c|c|c|c|c|c|c|c|c|c|c|c|}
\hline \multirow{2}{*}{\multicolumn{2}{|c|}{ ercentile }} & \multicolumn{13}{|c|}{ Age (Years) } \\
\hline & & $18-22$ & $23-27$ & $28-32$ & $33-37$ & $38-42$ & $43-47$ & $48-52$ & $53-57$ & $58-62$ & $63-67$ & $68-72$ & $73-77$ & $>77$ \\
\hline \multirow{13}{*}{ 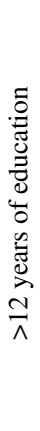 } & 95 & - & - & - & - & - & - & - & 20.0 & 20.0 & 20.0 & 20.0 & 19.8 & 19.5 \\
\hline & 90 & - & - & - & - & 20.0 & 20.0 & 20.0 & 19.7 & 19.4 & 19.1 & 18.8 & 18.5 & 18.1 \\
\hline & 85 & - & - & 20.0 & 20.0 & 19.8 & 19.5 & 19.2 & 18.8 & 18.5 & 18.2 & 17.9 & 17.6 & 17.3 \\
\hline & 80 & 20.0 & 20.0 & 19.7 & 19.4 & 19.1 & 18.7 & 18.4 & 18.1 & 17.8 & 17.5 & 17.2 & 16.8 & 16.5 \\
\hline & 70 & 19.2 & 18.8 & 18.5 & 18.2 & 17.9 & 17.6 & 17.3 & 16.9 & 16.6 & 16.3 & 16.0 & 15.7 & 15.3 \\
\hline & 60 & 18.2 & 17.8 & 17.5 & 17.2 & 16.9 & 16.6 & 16.3 & 15.9 & 15.6 & 15.3 & 15.0 & 14.7 & 14.4 \\
\hline & 50 & 17.2 & 16.9 & 16.6 & 16.3 & 16.0 & 15.7 & 15.3 & 15.0 & 14.7 & 14.4 & 14.1 & 13.8 & 13.4 \\
\hline & 40 & 16.3 & 16.0 & 15.7 & 15.4 & 15.1 & 14.7 & 14.4 & 14.1 & 13.8 & 13.5 & 13.2 & 12.8 & 12.5 \\
\hline & 30 & 15.3 & 15.0 & 14.7 & 14.4 & 14.1 & 13.7 & 13.4 & 13.1 & 12.8 & 12.5 & 12.2 & 11.8 & 11.5 \\
\hline & 20 & 14.1 & 13.8 & 13.5 & 13.2 & 12.9 & 12.6 & 12.2 & 11.9 & 11.6 & 11.3 & 11.0 & 10.7 & 10.3 \\
\hline & 15 & 13.4 & 13.1 & 12.8 & 12.5 & 12.1 & 11.8 & 11.5 & 11.2 & 10.9 & 10.6 & 10.2 & 9.9 & 9.6 \\
\hline & 10 & 12.5 & 12.2 & 11.9 & 11.6 & 11.3 & 10.9 & 10.6 & 10.3 & 10.0 & 9.7 & 9.4 & 9.0 & 8.7 \\
\hline & 5 & 11.2 & 10.9 & 10.6 & 10.3 & 9.9 & 9.6 & 9.3 & 9.0 & 8.7 & 8.4 & 8.0 & 7.7 & 7.4 \\
\hline \multirow{13}{*}{ 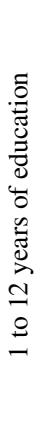 } & 95 & 20.0 & 20.0 & 20.0 & 20.0 & 19.8 & 19.5 & 19.2 & 18.8 & 18.5 & 18.2 & 17.9 & 17.6 & 17.2 \\
\hline & 90 & 19.7 & 19.4 & 19.1 & 18.8 & 18.5 & 18.1 & 17.8 & 17.5 & 17.2 & 16.9 & 16.6 & 16.2 & 15.9 \\
\hline & 85 & 18.8 & 18.5 & 18.2 & 17.9 & 17.6 & 17.3 & 16.9 & 16.6 & 16.3 & 16.0 & 15.7 & 15.4 & 15.0 \\
\hline & 80 & 18.1 & 17.8 & 17.5 & 17.2 & 16.8 & 16.5 & 16.2 & 15.9 & 15.6 & 15.3 & 14.9 & 14.6 & 14.3 \\
\hline & 70 & 16.9 & 16.6 & 16.3 & 16.0 & 15.7 & 15.3 & 15.0 & 14.7 & 14.4 & 14.1 & 13.8 & 13.4 & 13.1 \\
\hline & 60 & 15.9 & 15.6 & 15.3 & 15.0 & 14.7 & 14.4 & 14.0 & 13.7 & 13.4 & 13.1 & 12.8 & 12.5 & 12.1 \\
\hline & 50 & 15.0 & 14.7 & 14.4 & 14.1 & 13.8 & 13.4 & 13.1 & 12.8 & 12.5 & 12.2 & 11.8 & 11.5 & 11.2 \\
\hline & 40 & 14.1 & 13.8 & 13.5 & 13.1 & 12.8 & 12.5 & 12.2 & 11.9 & 11.6 & 11.2 & 10.9 & 10.6 & 10.3 \\
\hline & 30 & 13.1 & 12.8 & 12.5 & 12.2 & 11.8 & 11.5 & 11.2 & 10.9 & 10.6 & 10.3 & 9.9 & 9.6 & 9.3 \\
\hline & 20 & 11.9 & 11.6 & 11.3 & 11.0 & 10.7 & 10.3 & 10.0 & 9.7 & 9.4 & 9.1 & 8.8 & 8.4 & 8.1 \\
\hline & 15 & 11.2 & 10.9 & 10.6 & 10.2 & 9.9 & 9.6 & 9.3 & 9.0 & 8.7 & 8.3 & 8.0 & 7.7 & 7.4 \\
\hline & 10 & 10.3 & 10.0 & 9.7 & 9.4 & 9.0 & 8.7 & 8.4 & 8.1 & 7.8 & 7.5 & 7.1 & 6.8 & 6.5 \\
\hline & 5 & 9.0 & 8.7 & 8.4 & 8.0 & 7.7 & 7.4 & 7.1 & 6.8 & 6.4 & 6.1 & 5.8 & 5.5 & 5.2 \\
\hline
\end{tabular}

Table A4

Normative data for the BTA stratified by age and education levels for CUBA

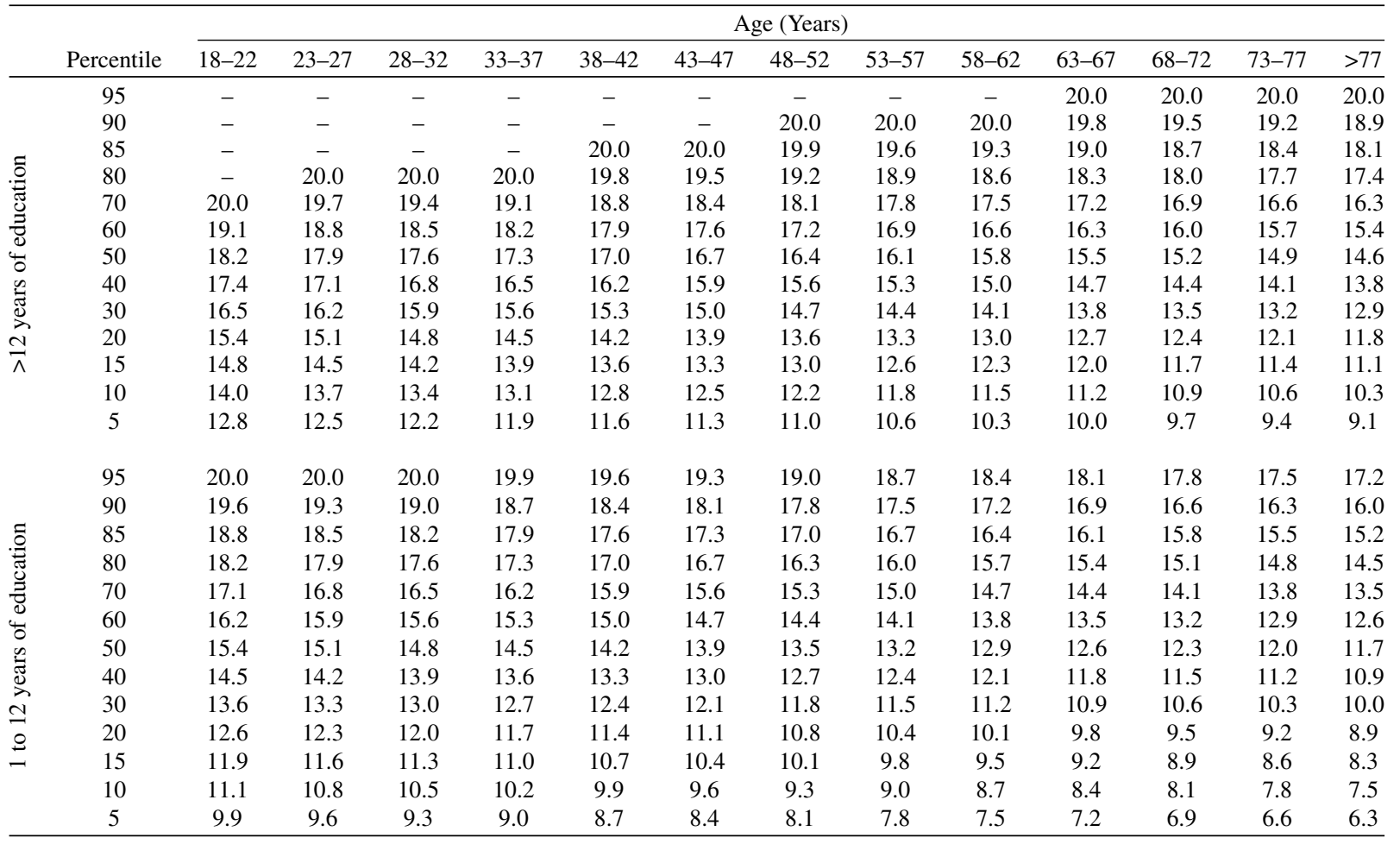


Table A5

Normative data for the BTA stratified by age and education levels for EL SALVADOR

\begin{tabular}{|c|c|c|c|c|c|c|c|c|c|c|c|c|c|c|}
\hline & \multirow[b]{2}{*}{ Percentile } & \multicolumn{13}{|c|}{ Age (Years) } \\
\hline & & $18-22$ & $23-27$ & $28-32$ & $33-37$ & $38-42$ & $43-47$ & $48-52$ & $53-57$ & $58-62$ & $63-67$ & $68-72$ & $73-77$ & $>77$ \\
\hline \multirow{13}{*}{ 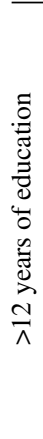 } & 95 & - & - & - & - & - & - & - & - & - & 20.0 & 20.0 & 20.0 & 20.0 \\
\hline & 90 & - & - & - & - & - & - & 20.0 & 20.0 & 20.0 & 19.9 & 19.6 & 19.3 & 19.0 \\
\hline & 85 & - & - & - & 20.0 & 20.0 & 20.0 & 19.8 & 19.5 & 19.3 & 19.0 & 18.7 & 18.4 & 18.1 \\
\hline & 80 & 20.0 & 20.0 & 20.0 & 19.9 & 19.6 & 19.4 & 19.1 & 18.8 & 18.5 & 18.2 & 18.0 & 17.7 & 17.4 \\
\hline & 70 & 19.6 & 19.3 & 19.0 & 18.7 & 18.5 & 18.2 & 17.9 & 17.6 & 17.3 & 17.1 & 16.8 & 16.5 & 16.2 \\
\hline & 60 & 18.6 & 18.3 & 18.0 & 17.8 & 17.5 & 17.2 & 16.9 & 16.6 & 16.4 & 16.1 & 15.8 & 15.5 & 15.2 \\
\hline & 50 & 17.7 & 17.4 & 17.1 & 16.8 & 16.6 & 16.3 & 16.0 & 15.7 & 15.4 & 15.2 & 14.9 & 14.6 & 14.3 \\
\hline & 40 & 16.8 & 16.5 & 16.2 & 15.9 & 15.6 & 15.4 & 15.1 & 14.8 & 14.5 & 14.2 & 14.0 & 13.7 & 13.4 \\
\hline & 30 & 15.8 & 15.5 & 15.2 & 14.9 & 14.6 & 14.4 & 14.1 & 13.8 & 13.5 & 13.2 & 13.0 & 12.7 & 12.4 \\
\hline & 20 & 14.6 & 14.3 & 14.0 & 13.8 & 13.5 & 13.2 & 12.9 & 12.6 & 12.4 & 12.1 & 11.8 & 11.5 & 11.2 \\
\hline & 15 & 13.9 & 13.6 & 13.3 & 13.0 & 12.7 & 12.5 & 12.2 & 11.9 & 11.6 & 11.3 & 11.1 & 10.8 & 10.5 \\
\hline & 10 & 13.0 & 12.7 & 12.4 & 12.1 & 11.9 & 11.6 & 11.3 & 11.0 & 10.7 & 10.5 & 10.2 & 9.9 & 9.6 \\
\hline & 5 & 11.7 & 11.4 & 11.1 & 10.8 & 10.5 & 10.3 & 10.0 & 9.7 & 9.4 & 9.1 & 8.9 & 8.6 & 8.3 \\
\hline \multirow{13}{*}{ 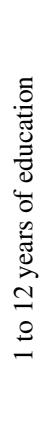 } & 95 & 18.7 & 18.5 & 18.2 & 17.9 & 17.6 & 17.3 & 17.1 & 16.8 & 16.5 & 16.2 & 15.9 & 15.7 & 15.4 \\
\hline & 90 & 17.4 & 17.1 & 16.9 & 16.6 & 16.3 & 16.0 & 15.7 & 15.5 & 15.2 & 14.9 & 14.6 & 14.3 & 14.1 \\
\hline & 85 & 16.5 & 16.3 & 16.0 & 15.7 & 15.4 & 15.1 & 14.9 & 14.6 & 14.3 & 14.0 & 13.7 & 13.5 & 13.2 \\
\hline & 80 & 15.8 & 15.5 & 15.2 & 15.0 & 14.7 & 14.4 & 14.1 & 13.8 & 13.6 & 13.3 & 13.0 & 12.7 & 12.4 \\
\hline & 70 & 14.6 & 14.3 & 14.1 & 13.8 & 13.5 & 13.2 & 12.9 & 12.7 & 12.4 & 12.1 & 11.8 & 11.5 & 11.3 \\
\hline & 60 & 13.6 & 13.4 & 13.1 & 12.8 & 12.5 & 12.2 & 12.0 & 11.7 & 11.4 & 11.1 & 10.8 & 10.6 & 10.3 \\
\hline & 50 & 12.7 & 12.4 & 12.2 & 11.9 & 11.6 & 11.3 & 11.0 & 10.8 & 10.5 & 10.2 & 9.9 & 9.6 & 9.4 \\
\hline & 40 & 11.8 & 11.5 & 11.2 & 11.0 & 10.7 & 10.4 & 10.1 & 9.8 & 9.6 & 9.3 & 9.0 & 8.7 & 8.4 \\
\hline & 30 & 10.8 & 10.5 & 10.2 & 10.0 & 9.7 & 9.4 & 9.1 & 8.8 & 8.6 & 8.3 & 8.0 & 7.7 & 7.4 \\
\hline & 20 & 9.6 & 9.4 & 9.1 & 8.8 & 8.5 & 8.2 & 8.0 & 7.7 & 7.4 & 7.1 & 6.8 & 6.5 & 6.3 \\
\hline & 15 & 8.9 & 8.6 & 8.3 & 8.1 & 7.8 & 7.5 & 7.2 & 6.9 & 6.7 & 6.4 & 6.1 & 5.8 & 5.5 \\
\hline & 10 & 8.0 & 7.7 & 7.5 & 7.2 & 6.9 & 6.6 & 6.3 & 6.1 & 5.8 & 5.5 & 5.2 & 4.9 & 4.7 \\
\hline & 5 & 6.7 & 6.4 & 6.1 & 5.9 & 5.6 & 5.3 & 5.0 & 4.7 & 4.5 & 4.2 & 3.9 & 3.6 & 3.3 \\
\hline
\end{tabular}

Table A6

Normative data for the BTA stratified by education levels for GUATEMALA

\begin{tabular}{lcc}
\hline Percentile & 1 to 12 years of education & $>12$ years of education \\
\hline 95 & 19.5 & - \\
90 & 18.3 & - \\
85 & 17.5 & 20.0 \\
80 & 16.8 & 19.5 \\
70 & 15.7 & 18.4 \\
60 & 14.8 & 17.5 \\
50 & 13.9 & 16.6 \\
40 & 13.1 & 15.8 \\
30 & 12.1 & 14.8 \\
20 & 11.1 & 13.7 \\
15 & 10.4 & 13.1 \\
10 & 9.6 & 12.2 \\
5 & 8.3 & 11.0 \\
\hline
\end{tabular}


Table A7

Normative data for the BTA stratified by age and education levels for HONDURAS

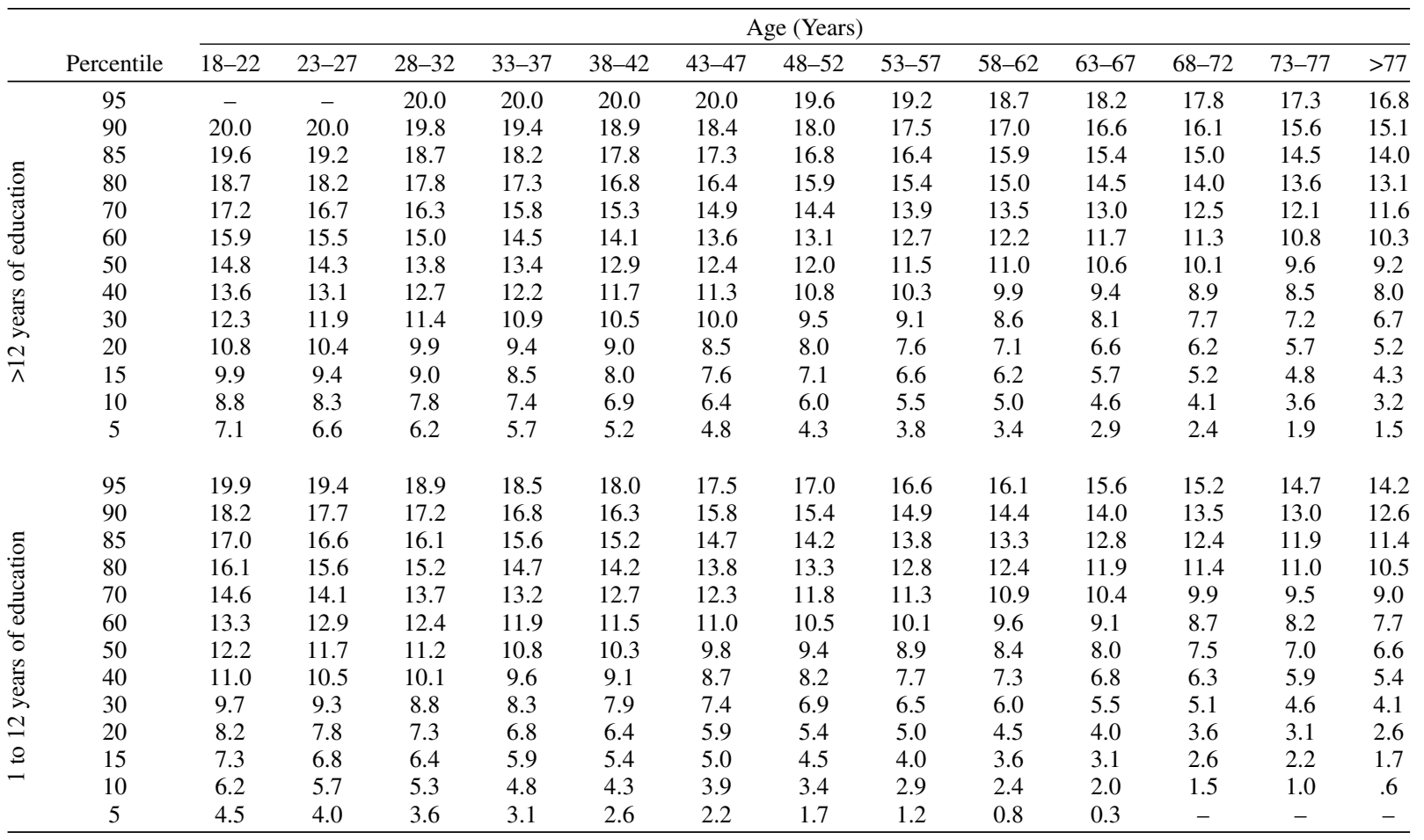

Table A8

Normative data for the BTA stratified by age and education levels for MEXICO

\begin{tabular}{|c|c|c|c|c|c|c|c|c|c|c|c|c|c|c|}
\hline \multirow{2}{*}{\multicolumn{2}{|c|}{ ercentile }} & \multicolumn{13}{|c|}{ Age (Years) } \\
\hline & & $18-22$ & $23-27$ & $28-32$ & $33-37$ & $38-42$ & $43-47$ & $48-52$ & $53-57$ & $58-62$ & $63-67$ & $68-72$ & $73-77$ & $>77$ \\
\hline \multirow{13}{*}{ 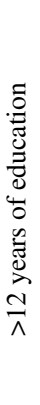 } & 95 & - & - & - & - & - & - & - & 20.0 & 20.0 & 20.0 & 20.0 & 20.0 & 19.8 \\
\hline & 90 & - & - & - & - & 20.0 & 20.0 & 20.0 & 19.8 & 19.5 & 19.3 & 19.0 & 18.8 & 18.5 \\
\hline & 85 & - & 20.0 & 20.0 & 20.0 & 19.7 & 19.4 & 19.2 & 18.9 & 18.7 & 18.4 & 18.1 & 17.9 & 17.6 \\
\hline & 80 & 20.0 & 19.8 & 19.5 & 19.2 & 19.0 & 18.7 & 18.5 & 18.2 & 17.9 & 17.7 & 17.4 & 17.1 & 16.9 \\
\hline & 70 & 18.8 & 18.6 & 18.3 & 18.1 & 17.8 & 17.5 & 17.3 & 17.0 & 16.8 & 16.5 & 16.2 & 16.0 & 15.7 \\
\hline & 60 & 17.9 & 17.6 & 17.3 & 17.1 & 16.8 & 16.6 & 16.3 & 16.0 & 15.8 & 15.5 & 15.3 & 15.0 & 14.7 \\
\hline & 50 & 16.9 & 16.7 & 16.4 & 16.2 & 15.9 & 15.6 & 15.4 & 15.1 & 14.9 & 14.6 & 14.3 & 14.1 & 13.8 \\
\hline & 40 & 16.0 & 15.8 & 15.5 & 15.2 & 15.0 & 14.7 & 14.5 & 14.2 & 13.9 & 13.7 & 13.4 & 13.2 & 12.9 \\
\hline & 30 & 15.0 & 14.8 & 14.5 & 14.3 & 14.0 & 13.7 & 13.5 & 13.2 & 13.0 & 12.7 & 12.4 & 12.2 & 11.9 \\
\hline & 20 & 13.9 & 13.6 & 13.4 & 13.1 & 12.8 & 12.6 & 12.3 & 12.1 & 11.8 & 11.5 & 11.3 & 11.0 & 10.7 \\
\hline & 15 & 13.1 & 12.9 & 12.6 & 12.4 & 12.1 & 11.8 & 11.6 & 11.3 & 11.1 & 10.8 & 10.5 & 10.3 & 10.0 \\
\hline & 10 & 12.3 & 12.0 & 11.7 & 11.5 & 11.2 & 11.0 & 10.7 & 10.4 & 10.2 & 9.9 & 9.7 & 9.4 & 9.1 \\
\hline & 5 & 11.0 & 10.7 & 10.4 & 10.2 & 9.9 & 9.6 & 9.4 & 9.1 & 8.9 & 8.6 & 8.3 & 8.1 & 7.8 \\
\hline \multirow{13}{*}{ 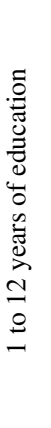 } & 95 & 20.0 & 20.0 & 20.0 & 20.0 & 20.0 & 20.0 & 20.0 & 19.9 & 19.7 & 19.4 & 19.1 & 18.9 & 18.6 \\
\hline & 90 & 20.0 & 20.0 & 19.9 & 19.6 & 19.4 & 19.1 & 18.9 & 18.6 & 18.3 & 18.1 & 17.8 & 17.6 & 17.3 \\
\hline & 85 & 19.5 & 19.3 & 19.0 & 18.8 & 18.5 & 18.2 & 18.0 & 17.7 & 17.5 & 17.2 & 16.9 & 16.7 & 16.4 \\
\hline & 80 & 18.8 & 18.6 & 18.3 & 18.0 & 17.8 & 17.5 & 17.3 & 17.0 & 16.7 & 16.5 & 16.2 & 15.9 & 15.7 \\
\hline & 70 & 17.6 & 17.4 & 17.1 & 16.9 & 16.6 & 16.3 & 16.1 & 15.8 & 15.6 & 15.3 & 15.0 & 14.8 & 14.5 \\
\hline & 60 & 16.7 & 16.4 & 16.1 & 15.9 & 15.6 & 15.4 & 15.1 & 14.8 & 14.6 & 14.3 & 14.1 & 13.8 & 13.5 \\
\hline & 50 & 15.7 & 15.5 & 15.2 & 15.0 & 14.7 & 14.4 & 14.2 & 13.9 & 13.7 & 13.4 & 13.1 & 12.9 & 12.6 \\
\hline & 40 & 14.8 & 14.6 & 14.3 & 14.0 & 13.8 & 13.5 & 13.3 & 13.0 & 12.7 & 12.5 & 12.2 & 12.0 & 11.7 \\
\hline & 30 & 13.8 & 13.6 & 13.3 & 13.1 & 12.8 & 12.5 & 12.3 & 12.0 & 11.8 & 11.5 & 11.2 & 11.0 & 10.7 \\
\hline & 20 & 12.7 & 12.4 & 12.2 & 11.9 & 11.6 & 11.4 & 11.1 & 10.9 & 10.6 & 10.3 & 10.1 & 9.8 & 9.5 \\
\hline & 15 & 11.9 & 11.7 & 11.4 & 11.2 & 10.9 & 10.6 & 10.4 & 10.1 & 9.9 & 9.6 & 9.3 & 9.1 & 8.8 \\
\hline & 10 & 11.1 & 10.8 & 10.5 & 10.3 & 10.0 & 9.8 & 9.5 & 9.2 & 9.0 & 8.7 & 8.5 & 8.2 & 7.9 \\
\hline & 5 & 9.8 & 9.5 & 9.2 & 9.0 & 8.7 & 8.4 & 8.2 & 7.9 & 7.7 & 7.4 & 7.1 & 6.9 & 6.6 \\
\hline
\end{tabular}


Table A9

Normative data for the BTA stratified by age and education levels for PARAGUAY

\begin{tabular}{|c|c|c|c|c|c|c|c|c|c|c|c|c|c|c|}
\hline & \multirow[b]{2}{*}{ Percentile } & \multicolumn{13}{|c|}{ Age (Years) } \\
\hline & & $18-22$ & $23-27$ & $28-32$ & $33-37$ & $38-42$ & $43-47$ & $48-52$ & $53-57$ & $58-62$ & $63-67$ & $68-72$ & $73-77$ & $>77$ \\
\hline \multirow{13}{*}{ 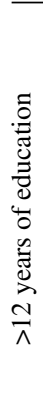 } & 95 & 17.1 & 16.9 & 16.7 & 16.4 & 16.2 & 16.0 & 15.8 & 15.5 & 15.3 & 15.1 & 14.9 & 14.7 & 14.4 \\
\hline & 90 & 16.1 & 15.9 & 15.7 & 15.5 & 15.3 & 15.0 & 14.8 & 14.6 & 14.4 & 14.1 & 13.9 & 13.7 & 13.5 \\
\hline & 85 & 15.5 & 15.3 & 15.1 & 14.8 & 14.6 & 14.4 & 14.2 & 14.0 & 13.7 & 13.5 & 13.3 & 13.1 & 12.8 \\
\hline & 80 & 15.0 & 14.8 & 14.5 & 14.3 & 14.1 & 13.9 & 13.6 & 13.4 & 13.2 & 13.0 & 12.8 & 12.5 & 12.3 \\
\hline & 70 & 14.1 & 13.9 & 13.7 & 13.5 & 13.2 & 13.0 & 12.8 & 12.6 & 12.4 & 12.1 & 11.9 & 11.7 & 11.5 \\
\hline & 60 & 13.4 & 13.2 & 13.0 & 12.7 & 12.5 & 12.3 & 12.1 & 11.9 & 11.6 & 11.4 & 11.2 & 11.0 & 10.7 \\
\hline & 50 & 12.7 & 12.5 & 12.3 & 12.1 & 11.9 & 11.6 & 11.4 & 11.2 & 11.0 & 10.8 & 10.5 & 10.3 & 10.1 \\
\hline & 40 & 12.1 & 11.9 & 11.6 & 11.4 & 11.2 & 11.0 & 10.8 & 10.5 & 10.3 & 10.1 & 9.9 & 9.6 & 9.4 \\
\hline & 30 & 11.4 & 11.2 & 10.9 & 10.7 & 10.5 & 10.3 & 10.0 & 9.8 & 9.6 & 9.4 & 9.2 & 8.9 & 8.7 \\
\hline & 20 & 10.5 & 10.3 & 10.1 & 9.9 & 9.6 & 9.4 & 9.2 & 9.0 & 8.7 & 8.5 & 8.3 & 8.1 & 7.9 \\
\hline & 15 & 10.0 & 9.8 & 9.6 & 9.3 & 9.1 & 8.9 & 8.7 & 8.4 & 8.2 & 8.0 & 7.8 & 7.6 & 7.3 \\
\hline & 10 & 9.4 & 9.1 & 8.9 & 8.7 & 8.5 & 8.2 & 8.0 & 7.8 & 7.6 & 7.4 & 7.1 & 6.9 & 6.7 \\
\hline & 5 & 8.4 & 8.2 & 8.0 & 7.7 & 7.5 & 7.3 & 7.1 & 6.9 & 6.6 & 6.4 & 6.2 & 6.0 & 5.7 \\
\hline \multirow{13}{*}{ 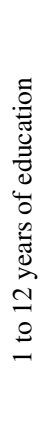 } & 95 & 12.3 & 12.1 & 11.9 & 11.6 & 11.4 & 11.2 & 11.0 & 10.7 & 10.5 & 10.3 & 10.1 & 9.9 & 9.6 \\
\hline & 90 & 11.3 & 11.1 & 10.9 & 10.7 & 10.5 & 10.2 & 10.0 & 9.8 & 9.6 & 9.4 & 9.1 & 8.9 & 8.7 \\
\hline & 85 & 10.7 & 10.5 & 10.3 & 10.0 & 9.8 & 9.6 & 9.4 & 9.2 & 8.9 & 8.7 & 8.5 & 8.3 & 8.0 \\
\hline & 80 & 10.2 & 10.0 & 9.7 & 9.5 & 9.3 & 9.1 & 8.9 & 8.6 & 8.4 & 8.2 & 8.0 & 7.7 & 7.5 \\
\hline & 70 & 9.3 & 9.1 & 8.9 & 8.7 & 8.4 & 8.2 & 8.0 & 7.8 & 7.6 & 7.3 & 7.1 & 6.9 & 6.7 \\
\hline & 60 & 8.6 & 8.4 & 8.2 & 8.0 & 7.7 & 7.5 & 7.3 & 7.1 & 6.8 & 6.6 & 6.4 & 6.2 & 6.0 \\
\hline & 50 & 8.0 & 7.7 & 7.5 & 7.3 & 7.1 & 6.8 & 6.6 & 6.4 & 6.2 & 6.0 & 5.7 & 5.5 & 5.3 \\
\hline & 40 & 7.3 & 7.1 & 6.9 & 6.6 & 6.4 & 6.2 & 6.0 & 5.7 & 5.5 & 5.3 & 5.1 & 4.9 & 4.6 \\
\hline & 30 & 6.6 & 6.4 & 6.1 & 5.9 & 5.7 & 5.5 & 5.2 & 5.0 & 4.8 & 4.6 & 4.4 & 4.1 & 3.9 \\
\hline & 20 & 5.7 & 5.5 & 5.3 & 5.1 & 4.8 & 4.6 & 4.4 & 4.2 & 4.0 & 3.7 & 3.5 & 3.3 & 3.1 \\
\hline & 15 & 5.2 & 5.0 & 4.8 & 4.5 & 4.3 & 4.1 & 3.9 & 3.6 & 3.4 & 3.2 & 3.0 & 2.8 & 2.5 \\
\hline & 10 & 4.6 & 4.3 & 4.1 & 3.9 & 3.7 & 3.5 & 3.2 & 3.0 & 2.8 & 2.6 & 2.3 & 2.1 & 1.9 \\
\hline & 5 & 3.6 & 3.4 & 3.2 & 2.9 & 2.7 & 2.5 & 2.3 & 2.1 & 1.8 & 1.6 & 1.4 & 1.2 & .9 \\
\hline
\end{tabular}

Table A10

Normative data for the BTA stratified by age and education levels for PERU

\begin{tabular}{|c|c|c|c|c|c|c|c|c|c|c|c|c|c|c|}
\hline & \multirow[b]{2}{*}{ Percentile } & \multicolumn{13}{|c|}{ Age (Years) } \\
\hline & & $18-22$ & $23-27$ & $28-32$ & $33-37$ & $38-42$ & $43-47$ & $48-52$ & $53-57$ & $58-62$ & $63-67$ & $68-72$ & $73-77$ & $>77$ \\
\hline \multirow{13}{*}{ 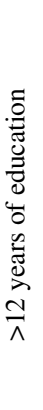 } & 95 & - & - & - & - & - & 20.0 & 20.0 & 20.0 & 20.0 & 20.0 & 19.8 & 19.7 & 19.5 \\
\hline & 90 & - & - & 20.0 & 20.0 & 20.0 & 19.8 & 19.6 & 19.4 & 19.2 & 19.0 & 18.8 & 18.6 & 18.4 \\
\hline & 85 & 20.0 & 20.0 & 19.7 & 19.5 & 19.3 & 19.1 & 18.9 & 18.7 & 18.5 & 18.3 & 18.1 & 17.9 & 17.7 \\
\hline & 80 & 19.6 & 19.4 & 19.2 & 19.0 & 18.8 & 18.6 & 18.4 & 18.2 & 18.0 & 17.8 & 17.6 & 17.4 & 17.2 \\
\hline & 70 & 18.6 & 18.4 & 18.2 & 18.0 & 17.8 & 17.6 & 17.4 & 17.2 & 17.0 & 16.8 & 16.7 & 16.5 & 16.3 \\
\hline & 60 & 17.9 & 17.7 & 17.5 & 17.3 & 17.1 & 16.9 & 16.7 & 16.5 & 16.3 & 16.1 & 15.9 & 15.7 & 15.5 \\
\hline & 50 & 17.2 & 17.0 & 16.8 & 16.6 & 16.4 & 16.2 & 16.0 & 15.8 & 15.6 & 15.4 & 15.2 & 15.0 & 14.8 \\
\hline & 40 & 16.4 & 16.2 & 16.0 & 15.8 & 15.6 & 15.4 & 15.2 & 15.0 & 14.8 & 14.7 & 14.5 & 14.3 & 14.1 \\
\hline & 30 & 15.7 & 15.5 & 15.3 & 15.1 & 14.9 & 14.7 & 14.5 & 14.3 & 14.1 & 13.9 & 13.7 & 13.5 & 13.3 \\
\hline & 20 & 14.8 & 14.6 & 14.4 & 14.2 & 14.0 & 13.8 & 13.6 & 13.4 & 13.2 & 13.0 & 12.8 & 12.6 & 12.4 \\
\hline & 15 & 14.2 & 14.0 & 13.8 & 13.6 & 13.4 & 13.2 & 13.0 & 12.8 & 12.6 & 12.4 & 12.2 & 12.0 & 11.8 \\
\hline & 10 & 13.5 & 13.3 & 13.1 & 12.9 & 12.7 & 12.5 & 12.3 & 12.1 & 11.9 & 11.7 & 11.5 & 11.3 & 11.1 \\
\hline & 5 & 12.5 & 12.3 & 12.1 & 11.9 & 11.7 & 11.5 & 11.3 & 11.1 & 10.9 & 10.7 & 10.5 & 10.3 & 10.1 \\
\hline \multirow{13}{*}{ 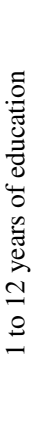 } & 95 & 19.1 & 18.9 & 18.7 & 18.5 & 18.3 & 18.1 & 17.9 & 17.7 & 17.5 & 17.3 & 17.1 & 16.9 & 16.7 \\
\hline & 90 & 18.0 & 17.8 & 17.7 & 17.5 & 17.3 & 17.1 & 16.9 & 16.7 & 16.5 & 16.3 & 16.1 & 15.9 & 15.7 \\
\hline & 85 & 17.4 & 17.2 & 17.0 & 16.8 & 16.6 & 16.4 & 16.2 & 16.0 & 15.8 & 15.6 & 15.4 & 15.2 & 15.0 \\
\hline & 80 & 16.8 & 16.6 & 16.4 & 16.2 & 16.0 & 15.8 & 15.6 & 15.4 & 15.2 & 15.0 & 14.8 & 14.6 & 14.4 \\
\hline & 70 & 15.9 & 15.7 & 15.5 & 15.3 & 15.1 & 14.9 & 14.7 & 14.5 & 14.3 & 14.1 & 13.9 & 13.7 & 13.5 \\
\hline & 60 & 15.1 & 14.9 & 14.7 & 14.5 & 14.3 & 14.1 & 13.9 & 13.7 & 13.5 & 13.3 & 13.1 & 12.9 & 12.7 \\
\hline & 50 & 14.4 & 14.2 & 14.0 & 13.8 & 13.6 & 13.4 & 13.2 & 13.0 & 12.8 & 12.6 & 12.4 & 12.2 & 12.0 \\
\hline & 40 & 13.7 & 13.5 & 13.3 & 13.1 & 12.9 & 12.7 & 12.5 & 12.3 & 12.1 & 11.9 & 11.7 & 11.5 & 11.3 \\
\hline & 30 & 12.9 & 12.7 & 12.5 & 12.3 & 12.1 & 11.9 & 11.7 & 11.5 & 11.3 & 11.1 & 10.9 & 10.7 & 10.5 \\
\hline & 20 & 12.0 & 11.8 & 11.6 & 11.4 & 11.2 & 11.0 & 10.8 & 10.6 & 10.4 & 10.2 & 10.0 & 9.8 & 9.6 \\
\hline & 15 & 11.4 & 11.2 & 11.0 & 10.8 & 10.6 & 10.4 & 10.2 & 10.0 & 9.8 & 9.6 & 9.4 & 9.2 & 9.0 \\
\hline & 10 & 10.7 & 10.5 & 10.3 & 10.1 & 9.9 & 9.7 & 9.5 & 9.3 & 9.1 & 8.9 & 8.7 & 8.5 & 8.3 \\
\hline & 5 & 9.7 & 9.5 & 9.3 & 9.1 & 8.9 & 8.7 & 8.5 & 8.3 & 8.1 & 7.9 & 7.7 & 7.5 & 7.3 \\
\hline
\end{tabular}


Table A11

Normative data for the BTA stratified by age and education levels for PUERTO RICO

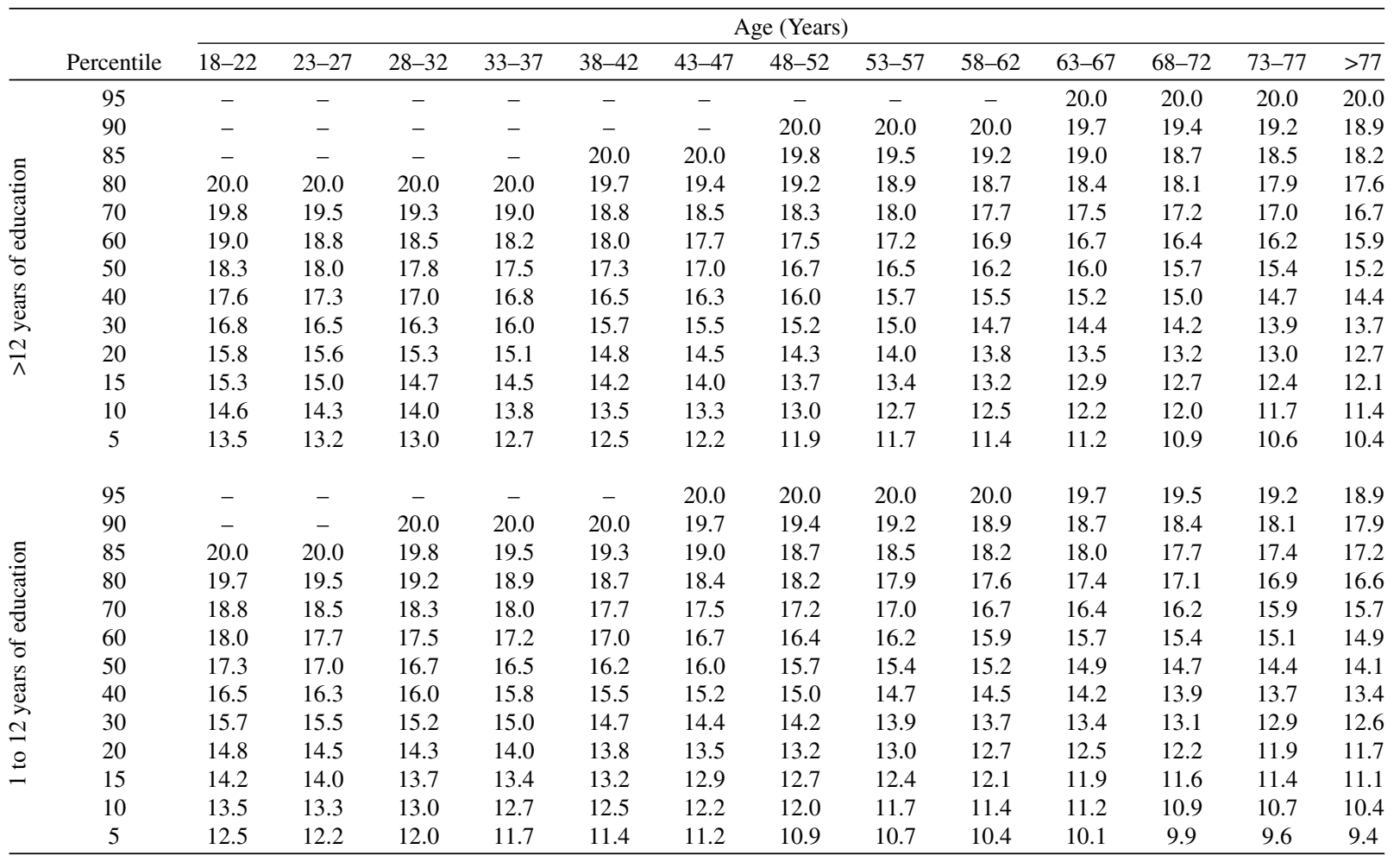

